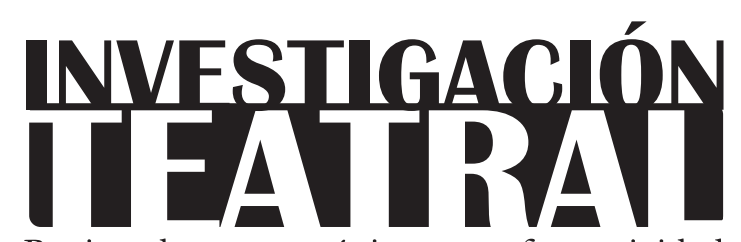

Revista de artes escénicas y performatividad

Vol. 11, Núm. 17

abril-septiembre 2020

Segunda época

ISSN impreso: 1665-8728

ISSN electrónico: 2594-0953

Universidad Veracruzana

\title{
Investigación-creación en el Teatro de Formas Animadas
}

\author{
Shaday Larios*
}

\footnotetext{
* Investigadora y creadora independiente, México. e-mail: microscopiateatro@gmail.com
}

Recibido: 03 de marzo de 2020

Aceptado: 15 de abril de 2020

Doi: $10.25009 /$ it.v11i17.2625 
INVESTIGACIÓNTEATRAL

Revista de artes escénicas y performatividad

Vol. 11, Núm. 17

abril-septiembre 2020
Investigación-creación en el

Teatro de Formas Animadas

Shaday Larios

\title{
Investigación-creación en el Teatro de Formas Animadas
}

\section{Resumen}

Existen distintos formatos de investigación-creación en el ámbito del teatro de formas animadas, así como creadores que imaginan marcos de visibilidad singulares para compartir sus propias búsquedas. En este artículo se exponen actitudes y tácticas detectables en un trabajo de investigación-creación (visibilidad, distanciamiento activo, singularidad, discurso encarnado) y se pregunta por la posibilidad de crear una red de investigadores-creadores de este tipo de "teatro animista" en Iberoamérica.

Palabras clave: Títeres, teatro de objetos, animismo, educación, conferencia escénica.

\section{Research and Creative Practice in the Theatre of Animated Forms}

\begin{abstract}
There exist different approaches to practice-based research in the field of Theatre of Animated Forms, and creators who imagine unique frameworks of visibility to share their own work. This article presents a range of tactics found in practice-based research, such as visibility, active distancing, uniqueness, and embodied discourse. The author suggests the possibility of creating a network of researchers-creators of "animist theater" in Latin America.
\end{abstract}

Keywords: Puppets, object theater, animism, education, lecture-performance. 


\section{Investigación-creación en el Teatro de Formas Animadas ${ }^{1}$}

$\mathrm{E}^{n}$ n este texto, identifico una diversidad de prácticas comunes para quienes nos encontramos unidos por el hecho de indagar, bajo distintas aproximaciones, en la zona limítrofe que tensa los vínculos entre lo animado y lo inanimado. Sea cual sea nuestra perspectiva, nuestra poética, nuestro medio elegido de trabajo, movilizamos nuestras investigaciones en un territorio animista. Nos une la percepción animista del mundo transformada en escena. Nos convoca aquella "primera metafísica del ser humano", como lo escribió Charles Baudelaire, la que emergía cuando éramos niños y pensábamos que nuestros juguetes estaban vivos. Conforme nos hacíamos grandes y no se manifestaba una fuerza visible que los moviera solos, nos llevaba a romperlos para ver qué era lo que tenían adentro, encontrándonos de frente con la nada (56-57). Creo que los que hacemos teatro de formas animadas enunciamos nuestros mundos creativos desde esa ausencia originaria. Hundimos las manos en esa primera herida y nos une, de algún modo, la vieja pregunta por el alma.

Me parece que esta práctica, en todas sus ramificaciones, agita desde varias intensidades el concepto en sí de "animismo" y, bajo una interpretación compleja, podría plantearse como un cuestionamiento expandido y multiforme hacia la mirada colonialista que subyace en su acepción tradicional. Ésta, como suscribe el curador de arte Anselm Franke, estudioso y problematizador de la noción, está generalmente inscrita en un esquema evolutivo que va de lo primitivo a lo civilizado y se asocia en sus orígenes a las exploraciones antropológicas euro-

1 Este texto es la reescritura de una conferencia plenaria que presenté el 03 de mayo de 2019, en el marco del Séptimo Coloquio El Títere y las Artes Escénicas, organizado por la Universidad Veracruzana y Merequetengue Artes Vivas en Xalapa, Veracruz. 
peas del siglo XIX, encabezadas por el inglés Edward Tylor. Una idea de animismo fundamentada en un supuesto "error" o "incapacidad psíquica" por parte de las sociedades pre-modernas para poder distinguir entre lo vivo y lo inerte, el sujeto y el objeto, el interior y el exterior, lo activo y lo pasivo, lo racional y lo irracional, lo animado y lo inanimado. Acaso el teatro de formas animadas constituya, en su esencia, una reacción, un observatorio directo o indirecto de estas percepciones dualistas del mundo y, en el mejor de los casos, un modo de hacer vinculado a las reflexiones del neo-animismo, del nuevo materialismo, del realismo especulativo y del post-humanismo. Corrientes que cuestionan, por diferentes líneas de pensamiento, esta herencia dual en la construcción de los saberes dada en el modernismo y sus repercusiones en nuestras maneras de juzgar y habitar la realidad. Como lo menciona Franke:

Tratar el animismo no como una cuestión de creencia, sino más bien como una práctica de creación de límites [...] El animismo como un concepto incómodo ante las epistemologías occidentales y una provocación hacia nuestra percepción cotidiana [...] como provocación que desestabiliza el poder de las posiciones y las sumisiones de la materia hacia lo humano (párrafo 3$)^{2}$

Tal factor desestabilizador, entrometido en las jerarquías de poder entre lo humano y lo no humano, se presenta justamente como un fundamento del estado perceptivo que nos propone el sustrato de un campo de juego y de reflexión en común, ése que se despliega en la tipología de escenarios que aquí me ocupan, sin que por ello pierdan su singularidad. De ahí que me ciña al término Teatro de Formas Animadas ${ }^{3}$ como un espacio de diversidad, a su vez que incluyente.

El término fue acuñado, tentativamente, en 1991 por la titiritera-académica Ana María Amaral, brasileña, pionera en introducir este teatro en la formación de actores dentro de su país. ${ }^{4}$ Es, de cierta manera, el equivalente de lo que muchos investigadores y creadores europeos denominan "teatro de figuras", puesto que ambas acepciones remiten a un mundo más flexible y expansivo de lo inanimado en escena, del cual no se excluye ningún material, por lo que no necesariamente debe adoptar rasgos antropomórficos, como sucede en el teatro de títeres o en la "marionetización del objeto", aunque, según Amaral, la diferencia entre el TFA y el teatro de figuras radica en lo que se comprende como "forma" y como

2 La traducción del inglés al español de las partes de este texto son mías.

3 En adelante, abreviado como TFA.

4 Lo escribo como tentativa, porque al menos ése es el año en el que aparece la primera edición de su clásico libro Teatro de formas animadas, editado por la Universidad de Sao Paulo, aunque, posiblemente, el proceso de creación de la terminología anteceda a 1991. 
"figura". En su perspectiva, y basándose en argumentos platónicos y aristotélicos, la idea de forma resulta más adecuada en tanto que remite a una posible cualidad animada de la materia, a diferencia de la idea de figura, explica:

En el Teatro de formas animadas, los objetos y materiales inanimados (máscaras, muñecos, objetos o simples imágenes) ganan vida y pasan a representar esencias (por extensión de la energía vital del actor-manipulador). Se convierten en personajes, en seres animados, pierden sus características de cuerpo material inerte y adquieren ánima y transmiten contenidos-sustancias [...] Por lo tanto para nosotros, el término forma es más apropiado que el de figura, porque está acompañado de su cualidad animada, porque confiere esencia (o sustancia) del objeto por transferencia (o transposición) de esencia o sustancia (del actor). La figura es algo inerte sin alma, la forma es algo que contiene alma. En cuanto muñeco-objeto, objeto plástico, materia inanimada, su nombre podría ser figura, pero en cuanto cosa animada el nombre más correcto nos parece forma, forma animada (Amaral 243). ${ }^{5}$

En este escrito me reapropio de la noción de Amaral, no sólo porque concuerdo con sus pensamientos, sino porque también me interesa atender y divulgar la poco conocida mirada latinoamericana femenina en el ámbito. El TFA se comprende aquí, entonces, como un nombre que funciona a manera de punto de encuentro, de zona de convergencia para mirarnos como una especie de "gremio animista" de la escena y formatos afines, sin por ello pretender homogeneizar los medios creativos y sus técnicas (cuando las hay). Por lo tanto, comprendo que el fenómeno de la "transferencia" o "transposición" de lo animado hacia lo inanimado, dentro del TFA, se extiende y abarca otras poéticas contemporáneas que están en proceso de ser investigadas y conceptualizadas más a profundidad (aparte de las mencionadas por Amaral, que cuentan ya con una tradición). Por ejemplo, el teatro de los materiales; el live film animation (en donde entran también los vínculos con objetos tecnológicos); la marioneta contemporánea, el teatro con juguetes y muñecas; las formas de transferencia del que denomino "teatro de objetos documentales", cuyo eje es la memoria de nuestra cultura material y en el cual me inscribo como investigadora, creadora y pedagoga. En este último se activan transposiciones afectivas y sociales, dadas de por sí en la propia biografía del objeto y sus ciclos vitales. ${ }^{6}$

5 La traducción del portugués al español es mía.

6 Desde 2014, he reflexionado sobre el teatro de objetos documentales en varios sitios. Se puede encontrar una reflexión más extensa en el capítulo titulado "Los objetos documentales dentro y fuera de escena", incluido en mi libro Los objetos vivos. Escenarios de la materia indócil. México: Paso de Gato, pp. 249-371. 
INVESTIGACIÓNTEATRAL

Vol. 11, Núm. 17

abril-septiembre 2020
Investigación-creación en el

Teatro de Formas Animadas

Shaday Larios

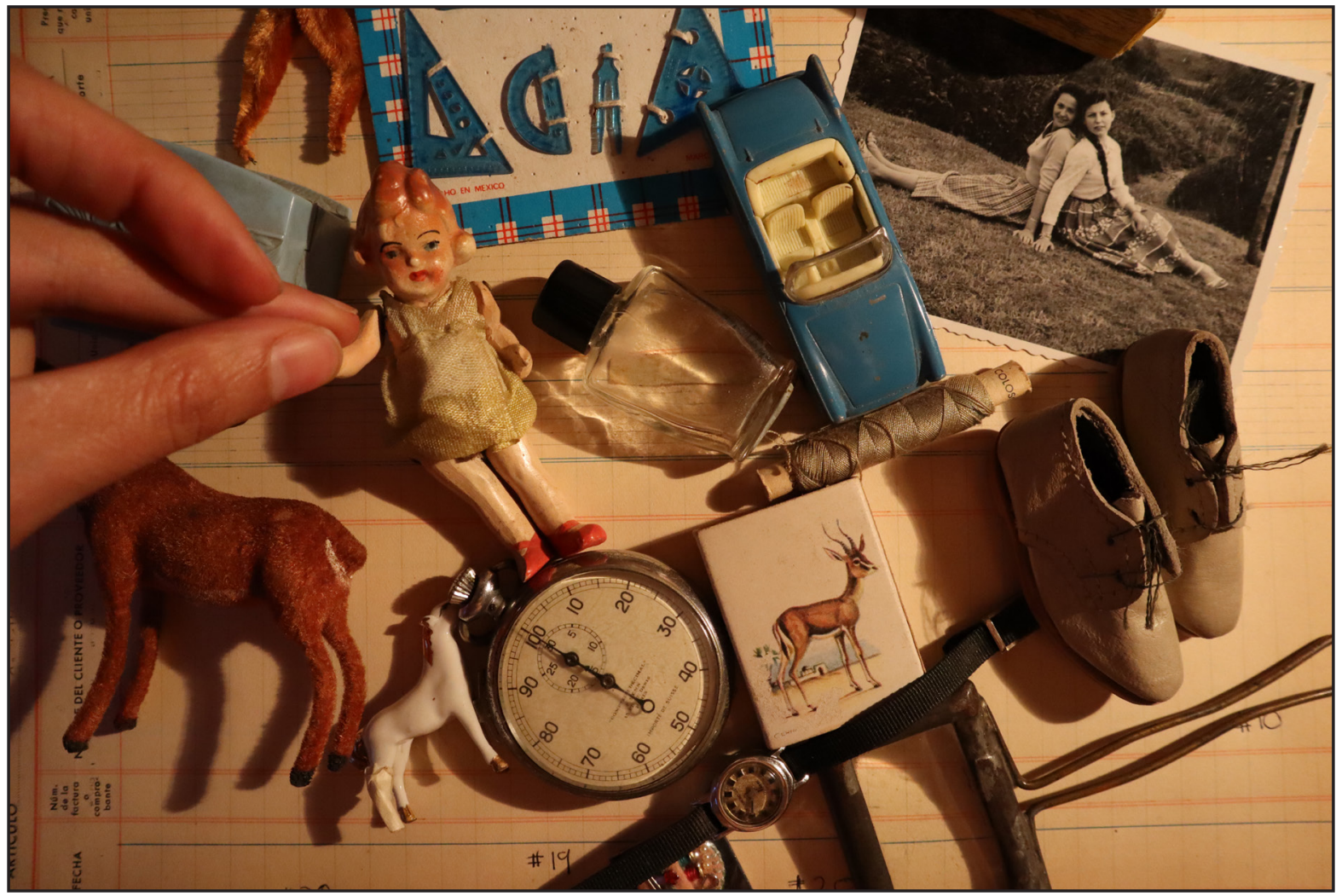

Bodegón de investigación. Oligor y Microscopía, Cortes, Navarra, España, 2020. Fotografía de Shaday Larios.

Con constancia, me pregunto qué dispositivos son los que producimos dentro de este territorio animista para compartir hallazgos y experiencias situadas durante las fases de los procesos creativos; cómo es que los matices de la vivencia imaginativa construida en las poéticas del TFA se vuelven comunicables y son susceptibles de adquirir el cuerpo de un aparato crítico compartido, capaz de tomar otros devenires epistemológicos independientes de un producto estético terminado; qué tejidos discursivos conformamos con las formalidades académicas o qué relaciones forjamos con los propios investigadores institucionales, o, por otro lado, qué tipo de variaciones y rupturas de los protocolos institucionales educativos podemos imaginar, cuando no se trata de una investigación inserta en un ámbito universitario en el que se tenga que cumplir con normativas específicas. Debido a esto último es que prefiero hablar de "investigación-creación”, más que de "investigación en artes", como una vertiente que no se refiere únicamente a un resultado que deba ser validado por una institución académica, sino también para referir aquellos otros que buscan sus 
propias maneras de auto-legitimación fuera de ella. Utilizo la idea de "investigación-creación" como término compuesto que podría involucrar entonces a ambos acercamientos para problematizar el mundo. A esta idea le es inherente una "perspectiva de la acción" o "perspectiva inmanente" si traigo aquí estas nociones del investigador de la Universidad de Leiden, Henk Borgdorff, al señalar lo que él denomina "investigación en las artes" en su tan referido texto "El debate en la investigación en las artes", donde afirma: "la que no asume la separación entre sujeto y objeto de conocimiento, que no contempla distancia entre el investigador y su práctica artística, ya que ésta es, en sí, un componente esencial tanto del proceso de investigación como de los resultados de la investigación" (30).

Debo aclarar que creo que la investigación académica es, según en qué contextos, un arduo y a veces doloroso proceso creativo, una negociación constante entre la subjetividad propia y la necesidad de un andamiaje de contención, organizado y sustentado. Una minuciosa labor que le concede su lugar debido a lo que nos antecede, como parte de una apasionante cadena humana de conocimiento, que nos lleva a percibir, una y otra vez, el carácter performativo de la memoria y de la Historia, esto es, su potencia multitemporal, su carácter de ser siempre un marco para comprender y reavivar nuestro presente. ¿Qué nos pueden enseñar los investigadores profesionales desde su propia creatividad metodológica, en este su hacer aparecer lo invisible, lo indecible, bajo su afán de precisión? ¿Cómo podríamos contaminarnos, trazar líneas transversales para ayudarnos mutuamente a producir nuevas enunciaciones dentro de nuestro campo? ¿Acaso quienes nos dedicamos a la investigación-creación en el TFA deberíamos producir formatos de comunicación cada vez más parecidos a aquello que investigamos (la mayoría de las veces relacionado con preguntas hacia las vitalidades de lo inanimado)? Si fuera así, deberíamos generar entonces formatos de conocimiento animados, tesis vivas, libros vivos, objetos de saber vivos que utilicen la teoría como una brújula más que como una clausura de la singularidad, habitar entonces la investigación, quizá como lo piensa el investigador español José Antonio Sánchez (y lo escribe al hablar del caso de la Residencia de Estudiantes de España), no como algo contradictorio a la vida, sino como una intensificación de la propia vida (Sánchez, "In-definiciones" 48). ${ }^{7}$

7 A propósito de traer aquí el nombre de José Antonio Sánchez, debo decir que esta conferencia-texto mantiene un diálogo abierto con distintos materiales y reflexiones que desde hace años generan Sánchez y Victoria Pérez Royo, en España, en torno a la investigación en artes. Principalmente, hay dos escritos que resuenan en esta reunión de reflexiones que intentan adentrar el debate en el contexto del territorio animista escénico, filtrados a su vez por mi propia experiencia en el campo. El primero es "La investigación en artes escénicas. Introducción”, en Cairon. Revista de Estudios de Danza, núm..13, 2010, pp. 5-13. Y el segundo es, también, una conferencia que se volvió texto publicable y que ha tenido, según lo relata el investigador, distintas versiones: "In-definiciones. El campo abierto de la investigación en artes". Jornadas de Investigación. Facultad de Artes de la Universidad de Antioquia. Medellín, 26 de agosto de 2013. Publi- 
De antemano se presupone que, detrás de todo acontecimiento de TFA, hay una temporalidad dedicada a un proceso, sostenida en una u otra capacidad económica (no siempre, lo sabemos). También hay una confluencia de subjetividades y afectos en un contexto socio-político localizado, un trabajo de decisiones estéticas, una discriminación de unos materiales frente a otros, de lo cual puede desprenderse una cierta postura ante un tema. A veces, hay trabajo de campo y, también, incertidumbres, tensiones, vivencias innombrables, intuiciones, revelaciones caóticas, lapsos de vacío, de prueba y error, según el modo de producción y de la idea que se tenga de método o de necesidad de estructuras predeterminadas. Hay gradaciones de lo que Peter Brook llamaba "presentimiento sin forma", de acuerdo al tipo de acuerdos estéticos establecidos en el interior de lo realizable. Es evidente que detrás de toda obra se encriptan conocimientos y saberes que, aunque la sostienen, no son siempre visibles en su materialidad final; por el contrario, está llena de intensificaciones que no confinan sus propagaciones epistemológicas a lo que se muestra en un producto acabado, anclado en las demandas de circulación del mercado, sino que pueden atender a otras traslaciones y estrategias de conocimiento y durabilidad. Entonces, en la mayoría de las creaciones de TFA podríamos identificar diferentes intrusiones del acto investigativo, aunque no de todas se desprende la voluntad de hacer lo que en este texto se entiende por investigación-creación. Esta voluntad se ve atravesada por fuerzas, actitudes y tácticas detectables e interrelacionadas, aunque nunca idénticas, en el sujeto o sujetos que idean un dispositivo y que articularé en lo siguiente, sin ánimo de generalizar, sino de instigar interrogantes de lo que se propone en sí, que por momentos desborda el propio ámbito del TFA. Hablo también aquí desde mi propia experiencia no sólo como creadora, sino como docente que investiga el área. ${ }^{8}$

cada en Artes. La Revista, vol. 12, núm. 19, 2013, localizable en línea en el blog de José Antonio Sánchez: http://blog.uclm.es/joseasanchez/2013/08/27/in-definiciones-la-investigacion-en-artes-2013/

8 Trabajé durante cuatro años en la Maestría de Investigación de la Danza del Centro Nacional de Investigación de la Danza "José Limón", en el campo de creatividad, en el que me dediqué a acompañar a coreógrafos y bailarines en la sistematización de sus procesos creativos, así como a pensar la investigación artística. Impartí durante tres años el seminario en línea "Otras objetualidades en las prácticas escénicas del siglo xxı", dentro del Certificado en Teatralidad, cuerpo y textualidades contemporáneas en 17 Instituto de Estudios Críticos. He publicado dos libros sobre teatro de objetos desde la investigación-creación: Los objetos vivos. Escenarios de la materia indócil (México: Paso de Gato, 2018) y Detectives de objetos (Segovia: La uña rota, 2019). Coordiné el Circuito de Memoria Material y laboratorios de teatro de objetos documentales en varios países latinoamericanos que dieron como resultado escrituras colaborativas publicadas en distintas revistas. Para saber más de este último proceso, se puede consultar un diario audiovisual en el siguiente enlace: vimeo.com/350362188 


\section{Visibilidad}

La investigación-creación tiene lugar cuando hay un deseo de visibilizar una o todas las líneas que sustentan la búsqueda particular de uno o más procesos, para hacerlas re-aparecer en otros ámbitos culturales. No es posible ver germinar la investigación-creación sin una intención comunicativa, porque, de lo contrario, el acto creativo se ensimisma en lo que sería la práctica en sí y para sí, diluyéndose con el paso del tiempo debido a las dinámicas vertiginosas del mercado y de la auto-explotación laboral. O por la inercia del trabajo con el silencio y la ausencia de registros textuales en muchos sectores del gremio del TFA. En éstos, el registro se lleva a cabo en la memoria del cuerpo y se ejecuta desde ahí para después quedar solamente inscrito en la piel del performer. Como reflexiona Ana María Amaral en su libro, el TFA es un arte de la imagen y del movimiento, en donde la primera se coloca al nivel del texto y en donde el segundo es el impulso más importante que se recibe en el acto escénico (244-245). El silencio es, también, un primer acceso de atención hacia aquello que no tiene una voz por sí mismo, que suele pasar desapercibido en la vida cotidiana. Las palabras devienen sigilo o dramaturgia de cualidades cinéticas, en el anhelo de no invadir lo no-humano con la presencia humana y, así, permitirle descubrir un lenguaje propio. "Los títeres guían nuestra atención sin palabras. El silencio marionetístico es una retirada del ser humano para permitir que la audiencia note otras cosas como los objetos, el mundo natural". ${ }^{9}$ Esta característica, que no puede considerarse un rasgo absoluto del TFA (porque hay muchas excepciones, como lo veremos), aunque sí tiene cierto predominio, entabla un vínculo particular entre la idea de registro verbal y proceso creativo por el cual tienden a anularse las voluntades de transmitir por escrito una investigación. Pero, por otro lado, esa carencia se decanta en el invento de ejercicios prácticos para la escena, compartidos en talleres u otras prácticas docentes, que tendrán su continuidad de boca en boca o de práctica en práctica. No siempre un texto tiene por qué ser la única vía de acceso a una investigación-creación en el TFA, si tomamos en cuenta las dimensiones que puede cobrar el silencio en el terreno animista de la escena.

Sea como sea, con un mediador textual o no, en quien investiga-crea se da la voluntad de hacer visible un hallazgo que lleva la latencia de la aportación a un gremio que, por lo demás, no es prolífico en estudios rigurosos en habla hispana a nivel institucional y cuenta

$9 \quad$ Ésta es una reflexión extraída de un grupo de pensamiento anónimo en torno al texto y el silencio en el mundo de los títeres dentro del Festival Internacional de la Marioneta, celebrado en Charleville-Mézières en 2019. El encuentro fue organizado por THEMAA. La localicé en el siguiente enlace: puppetcentre.org. uk/animations-online/frontpage/text-and-silence 
INVESTIGACIÓNTEATRAL

Revista de artes escénicas y performatividad

Vol. 11, Núm. 17

abril-septiembre 2020
Investigación-creación en el

Teatro de Formas Animadas

Shaday Larios

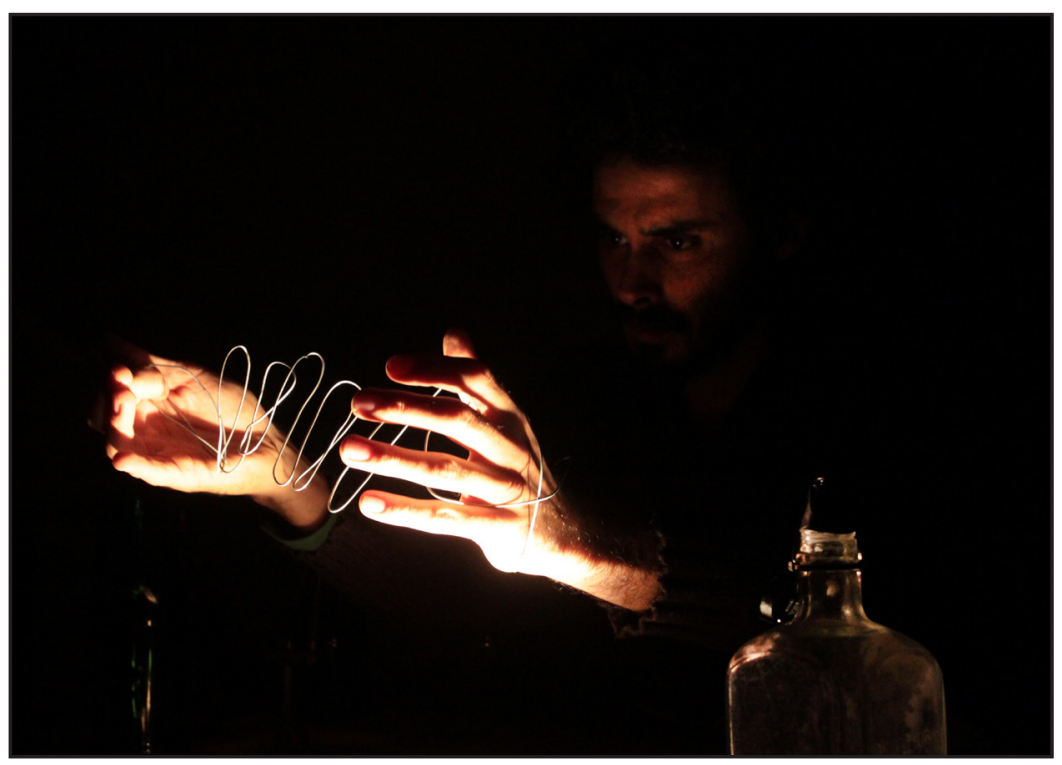

Insomni de Xavier Bobés. Barcelona, España, 2011. Fotorafía de Àlex Torguet.

con escasos espacios educativos oficiales en Iberoamérica. ¿Cómo la investigación-creación, en el TFA, puede llegar a convertirse, con el tiempo, en investigación para las artes o al servicio de las artes y cuáles son sus soportes de comunicación? Lo ejemplificaré después, sin afán de normativizar los hallazgos de la investigación-creación y hacerlos entrar en un sistema instrumental que los tecnifique o los reduzca, llevándolos a perder la vitalidad que les da la multiplicidad contextual. ¿Cómo mantenerse en un constante proceso de apertura crítica ante el hecho de intentar contener la experiencia en un objeto de conocimiento con el que en principio no se tiene distancia?

\section{Distanciamiento activo}

La investigación-creación acontece (ya no nada más en el TFA) cuando existe un constante auto-cuestionamiento y una "auto-vigilancia" epistemológica; es decir, el cómo yo me relaciono con el conocimiento preexistente, aquél que me antecede y cómo lo asimilo hacia el presente, hacia lo propio. En cómo genero mis propias lecturas y asociaciones, o si lo que hago es repetir e imitar una técnica, una sistematización que aprendí en otro lado o un acoplamiento de ambas dimensiones cognitivas. Comienza cuando emprendo un auto-análisis, una radiografía para desentrañar mis referentes y aprehensiones, que no siempre aparecen de manera consciente durante un proceso, sino sólo después, puesto que existe un distan- 
ciamiento de lo vivido, y puede llegar a comprenderse con la facilidad con la que se analiza lo que no es propio. ¿Cómo transito de lo interno hacia lo externo? ¿Cómo modelo objetos de conocimiento que surgen de la vivencia más íntima? El proceso de distanciamiento implica un trabajo psíquico, un esfuerzo imaginativo que se vuelve una práctica, una habilidad. Evidentemente, no se trata sólo de distanciarse en el espacio y en el tiempo, de revisar lo hecho en otros soportes (videos, diarios, bitácoras, etcétera), es también un modo de estar, un "distanciamiento activo", simultáneo a la praxis. Escribo en tiempo real, escribo con el pensamiento, estoy afuera y estoy adentro a la vez. Un estado del ser en experiencia en donde el desfase del instante co-presente se vuelve unidad de conocimiento. Estoy en el lugar de los hechos, pero también me encuentro traduciendo la vivencia y testificaré, desde la implicación, cómo se da una red relacional de saberes que envuelven el hecho creativo que acoge a mi cuerpo.

A veces, en el esfuerzo por traducir hay una especie de duelo, porque aquello que formaba una sensible gestación recóndita (apenas nombrable, apenas describible) con el cambio de perspectiva adopta al fin una forma. Viaja de lo íntimo hacia lo público, termina por ser materia transferible para la re-apropiación de los demás y con suerte tiene la potencia de formularse como concepto.

\section{Singularidad}

Al practicar el tránsito entre dimensiones teóricas y prácticas en la investigación-creación y ejercer un desdoblamiento consciente de la experiencia escénica, tiendo un puente personalizado entre posicionamientos. Éste puede llegar a constituir un método singular de exploración y visibilidad. Las conexiones entre teoría y práctica tienen un vaivén caprichoso, por momentos carente de toda lógica, y en esa indeterminación surge la singularidad que analiza y argumenta ese pasaje. Me parece que esta singularidad puede incentivar y contagiar la emergencia de otras metodologías singulares cuando se lleva al plano de la docencia. Como lo reflexionan José Antonio Sánchez y Victoria Pérez Royo: "La investigación en las artes debe servir entonces para superar el nivel de la transmisión de la técnica (sin que ésta sea por ello desplazada) al nivel de la transmisión de las metodologías creativas" ("La investigación en artes" 7). ¿Cómo fijar un acontecimiento, el acontecimiento del hallazgo? Habrá acaso un hallazgo de parámetros apropiados para cada singularidad procesual, objetividades movedizas que fluctuarán para re-hacerse con cada activación y permitir más que nada el diálogo con una comunidad af ín. Aunque siempre habrá algo que se fuga, siempre habrá una zona inaprehensible, incapturable. 


\section{Poner el cuerpo en nuestras palabras}

La frase que da título a esta sección es de la filósofa española Marina Garcés, quien promueve una filosofía que salga de las aulas y tome las calles. En distintos libros, Garcés habla de las corporalidades cansadas de los filósofos académicos, porque escriben y piensan encerrados en bibliotecas y estudios, perdiéndose de la vida. En sus palabras:

Hemos alimentado demasiadas palabras sin cuerpo, palabras dirigidas a las nubes o a los fantasmas [...] Son ellas las que no logran comprometernos, son ellas las que con su radicalidad de papel rehuyen el compromiso de nuestros estómagos. Poner el cuerpo en nuestras palabras significa decir lo que somos capaces de vivir o, a la inversa, hacernos capaces de decir lo que verdaderamente queremos vivir. Sólo palabras que asuman ese desafío tendrán la fuerza de comprometernos, de ponernos en un compromiso que haga estallar todas las obligaciones con las que cargamos en estas vidas de libre obediencia, de servidumbre voluntaria (67).

En la investigación-creación quizá no se puede dar una conciencia separada del mundo en el que se está, porque se pone el cuerpo en el centro de la experiencia. Y las palabras que nacen de ella pueden estar cargadas de la potencia vivida, tocada. Por eso, cuando llegan al papel, tal vez lleguen atravesadas por la fuerza de lo vivido. Inventan su propio lenguaje, si los términos para hacerle justicia a las sensaciones son inexistentes. La investigación-creación acontece cuando me asumo como un cuerpo que crea, que escribe, imagina y construye, pero también como un cuerpo que investiga y se auto-investiga. Soy un discurso encarnado, incorporado, atento a mis afecciones y percepciones, por lo cual la presencia de la primera persona se toma como un compromiso, como una responsabilidad. La necesidad de una toma de postura directa que pide no desaparecer, no atenuarse detrás de una acumulación de citas y voces ajenas, y, en todo caso, habitar la teoría desde la propia subjetividad. Emerge la tensión de un discurso que, a la vez que se convierte en objeto de conocimiento, es continuidad de mi propio cuerpo que se resiste a volverse objeto. ¿Cómo se pone el cuerpo en la investigación-creación del TFA a través de las palabras? ¿Hay una nueva politización de la corporalidad y el discurso al escribir desde el cuerpo, al hablar desde las afectaciones de lo que le pasa al propio cuerpo mientras se enfrenta a la construcción de un mundo imaginado? ¿Cómo forjar un lenguaje sigiloso, que atienda al estudio de lo que en muchas ocasiones carece de lenguaje hablado, como sucede en el TFA?

Con base en estas fuerzas, actitudes y tácticas (más el caudal de preguntas) que se interrelacionan y que son cuestionables, presento ahora una galería mínima para ejemplificar formatos de investigación-creación del TFA en Iberoamérica. Se trata de un recinto ima- 
ginado en el que podrían caber muchos otros nombres, ya que me resultan inabarcables en este espacio textual, y debido a que la galería tiene una naturaleza miniaturizante sin pretensiones exhaustivas.

\section{Galería mínima}

\section{Animistas escénicos que crean obras para visibilizar su investigación}

En esta sección expongo un recurso que utiliza el carácter performativo del formato conferencia para dejarse intervenir por los registros poéticos del TFA. Las charlas que siguen, en las que a veces entretejo entrevistas con los creadores, sugieren el tránsito de las clases magistrales hacia una suerte de lecture performances del territorio animista escénico, en donde los cuerpos encarnan la teoría y la despliegan en acciones que ejemplifican aquello de lo que hablan, a la vez que hacen visible un proceso de investigación. No se trata de demostraciones de trabajo, sino de formas que buscan, en sí mismas, ser espectáculos pautados que entran a circuitos de festivales profesionales, aunque también en escuelas y universidades. Sin embargo, son de tesitura permeable, son "autopoiéticos", en el sentido de que se retroalimentan de lo vivido y pueden variar datos y escenas según el contexto.

\section{Conferencia-espectáculo de Christian Carrignon / Théâtre d'objet: mode d'emploi (Cómo usar el teatro de objetos, 2010) ${ }^{10}$}

Esta conferencia escénica es una declaración de principios en torno al teatro de objetos (то), si se toma en cuenta, además, que el término, en sí, surge en el seno de la compañía del propio Christian Carrignon, en Francia, hacia 1980 (Théâtre de Cuisine). Y es, antes que nada, una manera de legitimar y esclarecer su propia manera de hacer, en la que ha sido una escuela de varias generaciones en torno al tratamiento escénico del objeto cotidiano. En esta conferencia, Carrignon extrae ejemplos de sus obras para hacer comprender su técnica y las raíces intuitivas que la sostienen. Por ejemplo, relata el hallazgo azaroso que influyó en lo que sería su concepción de la pequeña escala en el то, que es un fundamento clave del vínculo sujeto-objeto en esta poética. Un día de vacaciones, con la mirada perdida sobre la arena, vio un juguete, un camión rojo que se perdía en la inmensidad, o

10 En este enlace se pueden ver fragmentos de la conferencia-espectáculo: www.youtube.com/watch?v=9I$\mathrm{y} 42 \mathrm{gxQb} 24 \& \mathrm{t}=16 \mathrm{~s}$ 
mejor dicho: un camión de 33 toneladas perdido en un desierto. A partir de esa traslación, comprendió el factor de economía de elementos y proporciones que rige a su To y que ha devenido en una estrategia recurrente dentro de esta práctica en muchas otras compañías escénicas. Según cuenta, fue por impulso del encuentro fortuito con aquella imagen que desarrolló su técnica de los planos abiertos y cerrados en escena, parecidos al montaje cinematográfico, pero sin la vertiente consecutiva, sino más bien manteniendo la simultaneidad de las escalas. Por ello, es el actor quien, con sus acciones, dirige la mirada del espectador hacia el objeto o hacia el cuerpo del presentador del objeto. En otras palabras, establece su juego teatral entre lo grande y lo pequeño, exactamente como el cine que va y vuelve en la pantalla entre los planos más amplios y los más concentrados, saltando de un punto de vista a otro. El conferenciante es un investigador-creador activo en el espacio, que cuenta sus referentes teóricos, las maneras en las que su pensamiento traduce impulsos cotidianos en formulaciones escénicas, a la vez que monta micro-escenarios en donde vemos cómo funcionan teatralmente sus hallazgos. Por otro lado, Carrignon ha creado una alianza con Jean-Luc Matteóli, especialista en teatro de objetos, con quien ha escrito libros y artículos en conjunto, como la transcripción de un seminario impartido a dos, titulado como la conferencia-espectáculo Le théâtre d'objet: mode d'emploi (2005, CRDP de Bourgogne) o el libro Le théâtre d'objet: À la recherche du Théâtre d'objet (2009, THEMAA), entre otros textos.

\section{Conferencia escénica El alma del pueblo: una historia de amor entre el ser humano y los objetos (2013) de Títeres Etcétera ${ }^{11}$}

Enrique Lanz es director de Títeres Etcétera, compañía granadina fundada en 1981, y junto a la titiritera cubana Yanisbel V. Martínez (integrante del grupo desde el 2007), creó El alma del pueblo. La conferencia es una declaración de amor hacia su oficio, que tiene detrás muchos kilómetros recorridos en siete años de viajes y más de mil horas de filmación en distintas partes del mundo. La conferencia está apoyada por dichas exploraciones de campo realizadas en cine documental, con títeres y rutinas que interrumpen la posible seriedad del formato y la presencia narrativa de Yanisbel que cambia de registros interpretativos.

El alma del pueblo es un viaje sobre todo antropológico, reflexivo y sensible, a la vez que atraviesa por distintas tradiciones, usos y costumbres que dejan ver el vínculo de las

11 Se pueden consultar más detalles sobre la obra en el siguiente enlace: titeresetcetera.com/espectaculos/ el-alma-del-pueblo 
INVESTIGACIÓNTEATRAL

Vol. 11, Núm. 17

abril-septiembre 2020
Investigación-creación en el

Teatro de Formas Animadas

Shaday Larios

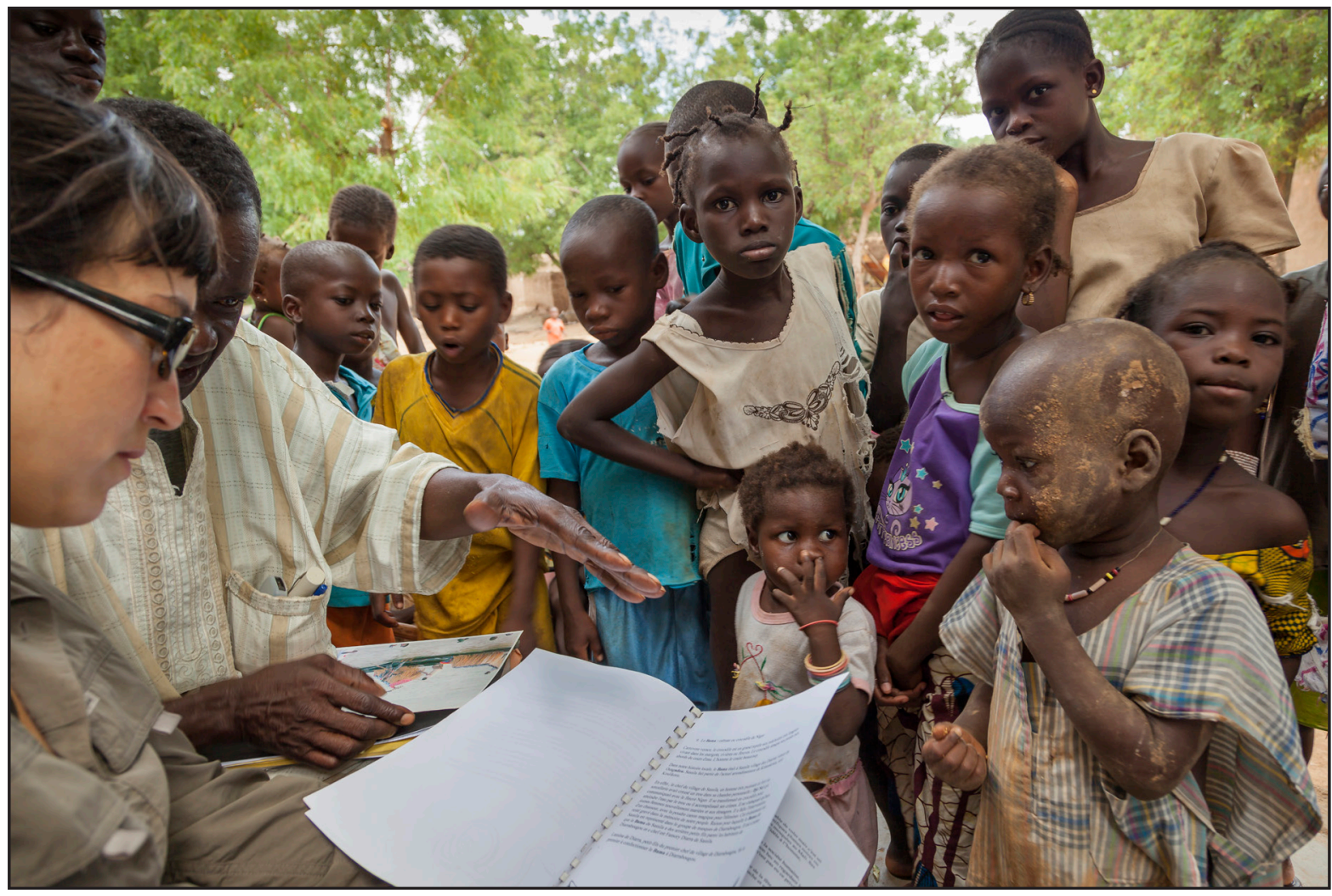

Proceso de investigación de El alma del pueblo. Títeres Etcétera, República de Mali, 2010. Fotografía de Enrique Lanz.

formas con sus usos sociales. Aquí, los titiriteros observan y registran detalles culturales de ritos y ceremonias y cómo estos impactan en la manipulación de la materialidad en su búsqueda por darle ánima: títeres habitados, figuras religiosas articuladas, belenes animados, máscaras, teatro de sombras, de títeres de muchas técnicas, colecciones privadas y públicas, talleres de construcción, obras, etcétera. Su investigación tiene que ver con un compromiso latente por la huella, por la memoria oculta del oficio que no se cuenta en los libros, que no está registrada en ningún lado y que sólo se hereda por vía oral o por enseñanza del hacer. Por ello, los investigadores-creadores ("titiriteros-antropólogos") se adentran en los espacios del secreto para recuperar, comparar y analizar cómo los títeres son una síntesis de la sociedad a la que pertenecen desde muchas perspectivas, aunque puedan parecerse a través de su comportamiento por su manera crítica de relacionarse con el mundo. Y esto lo hacen también a partir de una elaboración de preguntas constantes hacia el público que los acompaña, como tratando de cuestionarse a sí mismos, 
también, la importancia que ha tenido y tiene el TFA, así como sus prácticas ancestrales en la vida simbólica de las civilizaciones. Tal vez debido a su linaje, Lanz es un creador concentrado en preservar y cuidar la memoria de las tradiciones titiriteras y otras formas afines de animismo. Ya que, por las secuelas de la represión política de la Guerra Civil Española, a su abuelo, el dibujante, fotógrafo y escenógrafo para teatro de títeres (entre otras cosas) Hermenegildo Lanz, han intentado borrarle de la historia debido a sus ideas, lo mismo que a Manuel de Falla, quien fue exiliado, o como a Federico García Lorca, quien fue asesinado. Los tres fueron realizadores de la histórica función "Los Títeres de Cachipora" en 1923.

\section{Animistas escénicos que comunican sin escritura}

Un caso emblemático de este transmitir sin escritura es el del teatrista de objetos catalán Xavier Bobés. ${ }^{12}$ Desde hace más de 15 años investiga en la poética de los objetos de manera autodidacta y diseña dinámicas de trabajo grupal e individual a partir de los códigos que descubre en sus propias obras escénicas. Bobés es un reconocido inventor de herramientas, en lo que a gramática y dramaturgia manipulativa se refiere, que suele transmitir en múltiples talleres que imparte principalmente en España. En él, el cuerpo es un documento vivo donde se imprimen las palabras y los pensamientos para ser transformados en acción transferible.

El colega catalán me ofreció el siguiente testimonio que transcribo a continuación:

La investigación es intrínseca en el proceso de creación de cualquier proceso dramatúrgico con objetos, ya que cada nueva aventura creativa requiere de un nuevo aprendizaje acerca de un idioma con códigos y representaciones simbólicas singulares vinculadas a su materia, a su expresión coreográfica y a su capacidad evocadora. Me interesa explorar el vínculo entre lo íntimo y lo éxtimo, entre lo banal y lo sacro, entre lo estático y el movimiento. Este vínculo se expresa en todo y en todo momento; cualquier pista es un potencial indiscutible de representación artística. Mi experiencia es práctica, dialoga intensamente e inevitablemente con el pensar, unida a lo emocional

12 En la página web de su compañía Playground visual se pueden localizar fotografías y vídeos de su poética de los objetos: www.playgroundvisual.com/playgroundcas.html. En el apartado titulado "Desenterrar objetos. Documentar corporalmente la memoria de la ruina", de mi libro Los objetos vivos. Escenarios de la materia indócil, dedico un espacio a la reflexión de sus terminologías emergentes y sus procedimientos a partir de una de sus obras (271-278). 
también. Ese paso de dimensiones es caótico en un proceso de creación, sobre todo en su inicio, pero es mucho más clarividente en procesos ajenos, cuando el ente creador se dispone de una distancia con el material creador. En un proceso de creación, la experiencia formula su diario de acciones cotidianas casi inconscientemente, y en su apariencia caótica ordena pistas si el tiempo y la perseverancia lo permiten. En prácticas de docencia, este proceso es más inmediato. Intento que mi práctica sea física, analítica y sensorial a la vez. Intento que cada persona investigue desde lo más profundo y honesto, transitando entre la escucha grupal a la escucha individual, alejándose de motivaciones inmediatas basadas en el éxito o el fracaso. Mis talleres pueden resultar poco útiles a corto plazo, ya que dedico mucha energía a prácticas de juego y búsquedas íntimas que puedan despertar motivaciones más allá de las aulas: despertar la importancia del no hacer, el tocar desde lo mínimo, la composición desde la sencillez. Construir poco a poco un procedimiento del tocar que permita al individuo relajar el ego y los prejuicios, y disfrutar de la forma, la sugerencia, la imaginación (Entrevista).

\section{Animistas escénicos que reivindican a otros animistas a través de la escritura}

En esta sección de la galería expongo dos casos de investigadores-creadores que han dejado constancia, a través de la escritura de libros, de la necesidad del rescate de historias, testimonios y biografías trascendentes del TFA, que aún no habían sido documentadas. Aquí constatamos cómo los titiriteros se convierten en historiadores a partir de dispositivos de escritura singulares que buscan reivindicar esos vacíos.

\section{Toni Rumbau}

El titiritero y escritor catalán Toni Rumbau es autor de Rutas de Polichinela. Títeres y ciudades del mundo (Tarragona: Arola, 2013), una gran investigación-creación que funciona como un libro de viajes, al mismo tiempo que una búsqueda por documentar los distintos tratamientos que recibe el títere Polichinela en Europa, por medio de la crónica, las entrevistas y fragmentos de diario. Aquí, el titiritero es un flâneur que combina datos históricos del lugar en turno con las impresiones de sus derivas, más fotografías múltiples, relatos de encuentros y visitas a sitios a veces escasamente escritos o poco conocidos, a los que 
llega al tratar de rastrear las respuestas a las preguntas que guían su aventura: encontrar las simientes y resonancias culturales de este títere complejo. Rumbau inventa un dispositivo literario, desde su mirada animista, para contener su investigación, ahí fluye un lazo indisoluble entre los usos y variaciones que adopta Polichinela y los propios rasgos de la ciudad que lo transforma.

Rumbau trabaja como si el títere fuera una brújula, un espejo en el cual observar al ciudadano y viceversa, tanto de determinadas épocas como del presente. Así, encontramos capítulos-ciudades que son mapas alternos que construye el viajero: Dom Roberto (Lisboa, Porto), Pulcinella (Nápoles), Pupi (Palermo), Pantalone (Venecia), Kasparek (Praga, Brno), Mester Jakel (Copenhague), Vasilache (Bucarest), Kasperl (Múnich, Halle, Lübeck), Jan Klaassen (Ámsterdam), Punch (Londres), Polichinelle (París), Guignol (Lyon), Titella y Pericu (Barcelona), Don Cristóbal Polichinela (Madrid), Karagöz (Estambul, Beirut, Damasco, El Cairo). Rumbau es un versátil investigador-creador que trabaja en hacer circular y dar a conocer la diversidad del TFA a través de la revista digital Titeresante, ${ }^{13}$ que dirige, $\mathrm{o}$ de lo que fue Figuras del Desdoblamiento, una extensa exposición sobre TFA que curó en el 2015, en el Museo de Arte Santa Mónica de Barcelona, y de la cual resultó el libro Figures del desdoblament. Titelles, Màquines i fils, Comanegra (Barcelona, 2015), en el que distintos académicos fueron invitados a reflexionar sobre la metafísica de las marionetas y otros asuntos relacionados.

\section{Rubén Darío Salazar y Norge Espinosa}

Rubén Darío Salazar, actual director del Teatro Nacional de Guiñol de Cuba y director de la compañía Teatro de las Estaciones, junto a Zenén Calero, en Matanzas, es también un titiritero que hace una crónica de sus procesos creativos en distintas publicaciones. Me interesa destacar su investigación Mito, verdad y retablo: El Guiñol de los hermanos Camejo y Pepe Carril (2012) por su manufactura construida a lo largo de muchos años, su trabajo conjunto con el teatrólogo y dramaturgo cubano Norge Espinosa y por su afán de asentar una historia silenciada del TFA, de gran importancia en su país, trabajo que además ha sido merecedor de dos premios. ${ }^{14}$

La historia de los hermanos Camejo y Pepe Carril se encuentra desvanecida y aminorada debido a las represiones culturales que trajo el proceso de parametración en Cuba

13 www.titeresante.es

14 Premio de Teatrología Rine Leal (2009) y el Premio Nacional de la Crítica literaria (2013). 
INVESTIGACIÓNTEATRAL

Revista de artes escénicas y performatividad

Vol. 11, Núm. 17

abril-septiembre 2020
Investigación-creación en el

Teatro de Formas Animadas

Shaday Larios

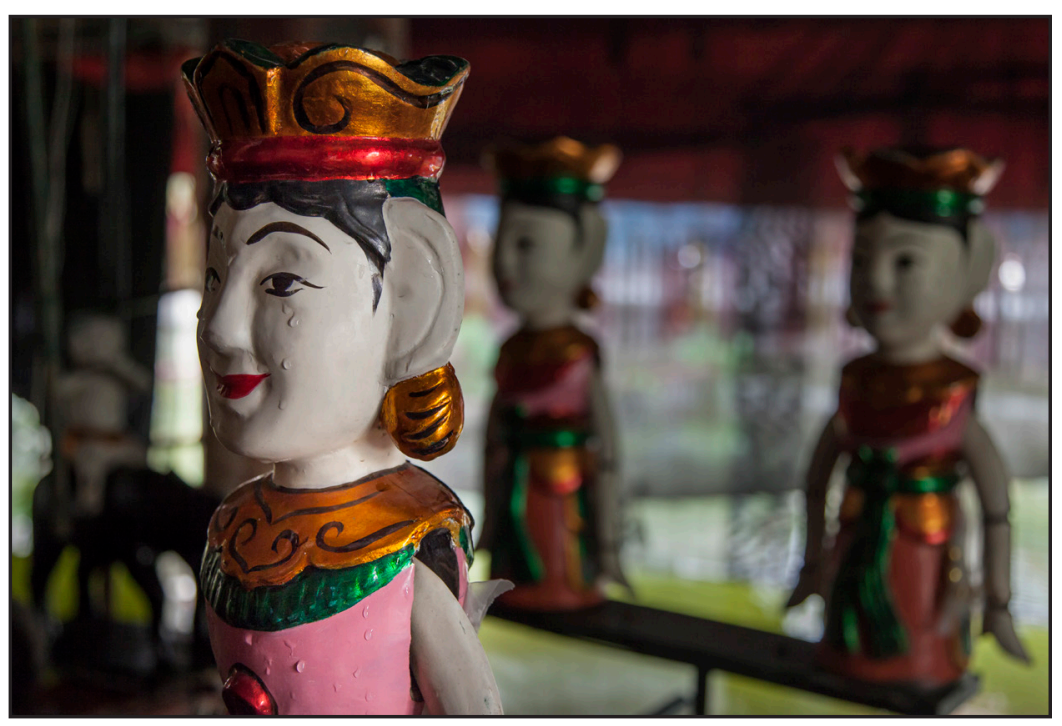

Proceso de investigación de El alma del pueblo. Títeres Etcétera. Vietnam, 2013.

Fotografía de Enrique Lanz.

(originada del Primer Congreso de Educación y Cultura en 1971). El impulso comienza así, como me explicó el propio Rubén Darío:

Las líneas del proceso de escritura comenzaron primero por la investigación, iniciada en 1998, hasta alcanzar 10 años de profundización en una historia fecunda, hermosa y triste, que pasa revista no sólo por la labor del más importante conjunto titiritero en la isla hasta la actualidad, sino por las raíces, tronco y ramas que extendió hacia todos los colectivos profesionales nacidos después. La chispa se prendió en 1991, con motivo de mi participación en el Festival Mundial de las Marionetas de Charleville-Mezieres, Francia. Allí me encontré con la directora artística rumana Margareta Niculescu, quien me preguntó que qué sabía yo de sus amigos y colegas Pepe, Carucha Camejo y Pepe Carril. No pude responderle con claridad, apenas sabía de la existencia de ellos. Breves notas, líneas, frases en algún libro o revista, no más. A partir de entonces comenzó el levantamiento de una época y una vida escénica, esencial en la historia de todo el teatro cubano todo (Salazar, entrevista).

Al levantamiento que siguió le corresponde una tarea de minuciosidad extrema y la problematización situada del arte del guiñol desde muchos niveles, para comprender las decisiones políticas que mueven a un país y su impacto en el imaginario social. La labor de rastreo de documentos probatorios para dar nombres, para definir evidencias, la transcripción de testimonios y piezas archivadas, el hilo riguroso con el que sale a la luz una historia que 
se creía perdida, el posicionamiento crítico y múltiple de los escritores de cómo se olvida y se construye la memoria en Cuba (en este caso, a través del oficio de los titiriteros y la censura), así como la precisión con la que se describen los contextos socio-políticos de la historia de la isla, han producido, sin duda, una de las mejores investigaciones que el TFA pueda tener, escrita por un dramaturgo y un titiritero. Y opino que es por la sinergia que aporta este último aspecto, el que la escritura construya una mirada tan especial en torno al conflicto, pues hay algo en el discurso que rezuma una fuerza de proximidad, aquella de quien defiende, se compromete y le hace justicia a la pasión por su propio oficio. O la teoría como intensificación de la propia vida.

\section{Animistas escénicos que escriben y enseñan}

En esta sección, le cedo la palabra a los testimonios de cuatro investigadores-creadores, reconocidos en el medio por sus publicaciones, obras, talleres y otras iniciativas pedagógicas. Su voz da respuesta a preguntas ideadas para esta zona de la galería, en donde les solicité conocer su visión sobre el significado de la investigación-creación a título personal, así como su vivencia de los pasajes entre dimensiones teóricas y prácticas. En esta área se percibe cómo el propio recorrido creativo se sistematiza para ponerse al servicio de los practicantes y estudiosos del TFA.

\section{Ana Alvarado (Buenos Aires) ${ }^{15}$}

Me interesa el teatro de objetos y su relación con el campo de la escena expandida. Es una reflexión que se inicia en el periodo en que formé parte del grupo El Periférico de Objetos (1989-2008) y que continué en mi obra posterior con la inclusión de la investigación sobre el encuentro de los objetos y los nuevos medios en la escena performativa. Participo en proyectos de investigación universitarios desde el año 2004 y he formado parte de investigaciones que tomaron como objeto de estudio la escena expandida y el teatro performático. Mi propia obra escénica fue inicialmente parte de esos proyectos y paulatinamente adquirí una formación

15 Ana Alvarado es autora de múltiples artículos de reflexión sobre el teatro de objetos publicados en revistas internacionales. Es autora del libro Teatro de objetos. Manual dramatúrgico (Buenos Aires: Instituto Nacional de Teatro, 2015), en colaboración con Mariana Gianella, y compiladora del libro Cosidad, Carnalidad y Virtualidad. Cuerpos y objetos en la Escena (Buenos Aires: Universidad Nacional de las Artes, 2018). 
para expresarme correctamente en la modalidad de un ensayo, ponencia o conferencia. He escrito artículos, editado libros de mi autoría o compilado materiales de otros autores. Hasta el momento, el eje principal de mis investigaciones ha sido el teatro objetual.

Actualmente, co-dirijo un proyecto que busca decodificar los sistemas y metodologías de la enseñanza universitaria en el área de la Dirección Escénica. Trato de que la tradicional dicotomía entre "teoría" y "práctica" se quiebre y que los procesos creativos abarquen todas las actividades que realizo. Busco crear espacios donde las certezas todavía no hayan clausurado la posibilidad de generar polémica. Por ejemplo, en el año 2011 fundé una carrera de posgrado en la Universidad Nacional de las Artes de Argentina (UNA) que se denomina Especialización en Teatro de Objetos, Interactividad y Nuevos Medios, con un cuerpo de profesores venido del teatro, los títeres, la crítica teatral y la investigación multimedial. Con ellos buscamos desde entonces generar eventos, reflexiones y un corpus teórico que dé cuenta de esta especificidad y que deje una puerta abierta al cambio permanente que se produce con el avance tecnológico.

\section{Carlos Converso (México) ${ }^{16}$}

Para mí, la investigación es una tarea fundamental. La experiencia a la luz de ésta se convierte en una fuente y receptáculo de prácticas y saberes adquiridos, muchos de ellos sedimentados, que se van iluminando a través de la indagación. Y, claro, sin descartar los valiosos aportes de colegas provenientes de otros ámbitos y disciplinas. Los temas que están en el foco de mi atención son: la animación como fenómeno y como técnica; la dramaturgia escénica, una modalidad de trabajo creativo muy propia de los titiriteros, y agregaría las convenciones y artificios escénicos en el teatro de títeres. La sistematización es, en gran medida, el reflexionar sobre la práctica y las múltiples experiencias; es una manera de mirar y analizar sobre el fenómeno escénico y sus materiales para hacerlo audible en un discurso que busca comunicar e interpretar procesos, aciertos y dificultades, causas, e incluso, azares. Procuro identificar pautas, señales, rastros de una linea de operatividad y procedimiento que nos muestra resultados que considero importantes y valiosos. También la lectura de las experiencias y formulaciones teóricas de otros colegas suele convertirse en material estimulante o detonador de reafirmaciones o controversias.

16 Carlos Converso es autor del clásico libro Entrenamiento del titiritero (México: Escenología, 2000), asî como un reconocido titiritero y profesor de larga trayectoria que comparte sus hallazgos en múltiples talleres por el mundo, como en su asignatura en la carrera de Teatro de la Universidad Veracruzana, Tópico de creación de títeres, y su Taller de puesta en escena. 
El paso de la práctica a la formulación teórica lo experimento como un proceso que aparece misterioso y escurridizo, como suele ser el mismo proceso creativo. A mi manera de ver, consiste en madurar una intuición que, en principio, es una tenue formulación. A veces, de manera velada o explícita, un día aparece el enunciado, la palabra que nombra y refiere el proceso o la secuencia del fenómeno, y más tarde es confirmada por la misma práctica y la reflexión.

\section{Rafael Curci (Uruguay) ${ }^{17}$}

Para mí, la investigación en el teatro de títeres y objetos es un territorio amplio que está en constante expansión. No tiene fronteras ni horizontes delimitados. Su topografía se intuye como plagada de interrogantes, misterios por revelar, pocas certezas, fluctuaciones y desafíos. Por eso, precisamos de exploradores. Muchos exploradores. Yo me considero apenas rastreador, un recolector de rastros, un observador de señales que reflexiona sobre las distintas incógnitas y paradigmas que se manifiestan mientras voy andando y haciendo. No dispongo de muchas herramientas y me guí básicamente por el olfato, la lógica y el sentido común; soy esencialmente un autodidacta intuitivo sin formación académica de ningún tipo. En mi caso, es la práctica sistemática del oficio la que detona la teoría y el pensamiento. A lo largo de los años, me propuse describir esta disciplina desde sus variantes técnicas, modalidades operativas y procedimientos. Se trata de un oficio que es tan viejo como el del sastre, el panadero o el del zapatero remendón. La ejecución medianamente aceptable de esta disciplina artística requiere de un profesional idóneo y entrenado, con mucha práctica y conocimientos variados; por eso, mis pesquisas abordan distintos saberes que atañen a este género.

Lo que intento trasmitir en mis libros y en los seminarios que dicto es analizar con detenimiento las condiciones prácticas y circunstanciales en las que aparecen y se desarrollan los conocimientos y habilidades propias del titiritero. En todos los casos, el análisis que propongo se centra en señalar y discernir sobre los distintos modos y procedimientos (exitosos o no) que han sido y son utilizados en escena por diferentes colegas, aunque gran parte de lo que llevo escrito son apenas reflexiones basadas en mi propia práctica y experiencia. Esas reflexiones tienen como objeto despertar el interés y profundizar en las varias áreas que

17 Rafael Curci es autor de los libros De los objetos y otras manipulaciones titiriteras (México: Libros de Godot, 2011), Títeres, objetos y otras metáforas (México: Libros de Godot, 2011), El titiritero en escena (México: Libros de Godot, 2015) y, de próxima aparición, el Bio-objeto en escena, entre otros. Es dramaturgo y titiritero e imparte numerosos talleres. Igualmente tiene un canal de YouTube en donde comparte clases por vía de esa plataforma: www.youtube.com/channel/UCtbYGG5x4J3jwlPji9qzWwg/videos 
le dan cuerpo y sustancia al arte del titiritero. No escribo con la idea de hacer un registro detallado de mis trabajos; eso daría como resultado un puñadito de diarios personales o derroteros de trabajo. Escribo y enseño con la idea que toda esa experiencia acumulada cumpla una función, una utilidad, que sea un punto de inflexión y de reflexión para alguien que busque alguna señal, un punto de partida o algún un rumbo. En cuanto a la práctica y la teoría, una es consecuencia de la otra, el tema es encontrar las palabras adecuadas para expresar las ideas que surgen desde el pensamiento, y que éstas, a su vez, sean comprensibles y útiles para el que las lee. Evito a toda costa formular teorías concretas o definitivas.

En el teatro de animación, no podemos tomar nada como concreto y definitivo porque es una disciplina dinámica, sustancialmente apócrifa y en estado de mutación constante. Me contento con señalar algunos rumbos por los que transité o insinuar caminos que estimulen otras miradas, que promuevan o detonen otras reflexiones. No disponemos de mucho material bibliográfico de apoyo en el área de los títeres y objetos, por lo que muchas veces avanzamos a ciegas, al tanteo. Aun así, siempre elijo algo y prefiero arriesgar, a sabiendas que puedo estar equivocado al formular una idea o una especulación.

\section{Javier Swedzky (Buenos Aires) ${ }^{18}$}

La investigación en este campo me permite crear mundos, explorar poéticas, desarrollar un lenguaje visual y liberar al texto de sus deberes informativos. Me permite conectarme y convocar al público en otros niveles, sensibles, conceptuales, que están por detrás de lo que se muestra en una obra, sosteniéndola. Me da una gran libertad para poder acercarme a zonas a las que, personalmente, me sería muy difícil acceder con cuerpos de personas: sentimientos extremos, olvidados, una cierta nostalgia por algo que no existió nunca. Me permite desarrollar un humor ácido, negro, a veces macabro, una poesía que no está hecha de palabras.

Trabajar con títeres y objetos también me da la oportunidad de pensar en un arte "integral" para el cual son solicitadas diferentes disciplinas, las artes plásticas, la actuación, la manipulación, y también la arqueología y los estudios de cultura material, y enmarcar un momento lúdico y creativo. A través de estos años, he podido llevar adelante mis propuestas, he materializado dudas, pesadillas y esperanzas en el espacio escénico. Estos mundos independientes me alivian, me consuelan. Pero intento que no quede dentro de un ecuación

18 Javier Swedzky es creador y docente, ha publicado diversos artículos de reflexión sobre la dramaturgia en el teatro de títeres y objetos. Dirige la revista digital EXPLORACIONES, textos breves para títeres y objetos de la Universidad Nacional de las Artes, en Buenos Aires. 
personal, si no que estas obras interpelen al espectador al que considero un igual, con el que intento compartir un momento de "agregación comunitaria" y de diálogo. Los objetos me parece que pueden contener ironía, el absurdo de nuestro cotidiano y pretensiones, la catástrofe y la deriva de nuestra sociedad. Considero a los objetos como partenaires. Doy clases desde hace muchos años, lo que me llevó a sistematizar tanto la práctica como el pensamiento acerca de la práctica. Con respecto a la práctica misma, orientada a la sensibilización del intérprete, a los potenciales del uso en escena de titeres y objetos, he desarrollado -inspirado en la antropología teatral- un camino que me permite pensar principios que se utilizan en muchas de las técnicas para hacer teatro con lo inanimado y, con ello, ahora intento escribir un libro.

Durante años le rehuí a la teoría teatral como algo que iba a coartar mi creatividad. No soy ajeno a una actitud que tienen muchos otros colegas. Enseñar en la universidad me obligó a ordenar lecturas, a buscar, a intentar entender y encontrar reflexiones y registros de experiencias que potenciaran mi trabajo y que me provocaran pasar al espacio a experimentar. Mientras leo, aparecen puentes inesperados, muchos de los cuales fueron ya pensados. Un ejemplo de esto es la idea de una dramaturgia fenomenológica, antes de conocer el libro de Werner Knoedgen. ${ }^{19}$

\section{Arsenal de preguntas}

O revolucionamos la universidad o ideamos tácticas que nos permitan el desarrollo de investigaciones en los intersticios, o bien la generación de espacios y contextos intermedios de investigación. No basta con hacer investigación, es preciso que los medios y contextos de investigación sean ellos mismos investigativos [...] interesantes y arriesgados.

José Antonio Sánchez

La confección de la galería previa tiene el pulso de lo inacabado. Me parece que está todo por hacer en el tema que he intentado apenas esbozar, en donde se comprende que cualquier intento de unidad es una ilusión aunque, no por ello, sea imposible imaginarnos una red de investigadores-creadores del TFA en Iberoamérica que sostenga futuras

19 N. del Ed. Werner Knoedgen es un teórico alemán, autor del libro El teatro imposible: hacia una fenomenología del teatro de figuras (1990). 
alianzas a varias escalas. Este texto es un minúsculo intento de cartografiar un territorio animista escénico fragmentario. Este territorio puede ser investigado y rastreado a partir de sus metodologías creativas para compartir "modelos" complejos de visibilidad de conocimientos entre educadores, creadores y estudiosos en este medio que cuenta con escasa bibliografía. Finalmente, de lo que se trata es de sondear y permanecer abiertos a las incontables maneras en las que el animismo, entendido como problema y dimensión humana, acompaña nuestras vidas.

Más que un epílogo, me interesa plantear un arsenal de preguntas que me permite entender lo que de conclusivo pueda tener una escritura: ¿Cómo generar espacios de mediación investigativa en los que podamos forjar una red de pensamiento cooperativo sobre el TFA, que conjuguen la formulación de teorías procedentes de la práctica y viceversa? ¿De qué modos producir estos espacios de encuentro y convergencia, en países donde no existen estudios profesionales sobre el campo que nos ocupa? ¿Qué tipo de políticas culturales permitirían este intercambio entre lo teórico y lo práctico dentro del TFA? ¿Cómo originar y replicar estos lugares autónomos en los cuáles compartir los saberes que producen nuestras prácticas, abriéndolos, además, al pensamiento académico en un trazo de reciprocidad entre formas de investigación, para aunar fuerzas e inventar espacios de coincidencia, espacios dónde estar juntos y producir un conocimiento común? ${ }^{20}$ ¿Qué compromisos socio-políticos comportan estas alianzas para su contexto determinado? ¿Qué ejercicios de imaginación podrían proponer plataformas de encuentro entre la teoría y la práctica capaces de convertirse en un continuo laboratorio epistemológico? ¿Cuáles serán los formatos de comunicabilidad de los futuros investigadores-creadores en el TFA dentro de la era de la inmaterialidad?

\section{Fuentes consultadas}

Alvarado, Ana. Entrevista personal. 24 de abril de 2019.

Amaral, Ana María. Teatro de Formas Animadas. Sao Paulo: Universidad de Sao Paulo, 2011.

Baudelaire, Charles. "Moral del juguete". Sobre marionetas, juguetes y muñecas. Traducido por Abel Vidal, Barcelona: Centellas, 2014, pp. 41-57.

Bobés Xavier. Entrevista personal 28 de marzo de 2019.

20 En este sentido, me parece que el coloquio El Títere y las Artes Escénicas, al cual se me invitó para compartir esta conferencia, es un espacio ideal para poder desarrollar intercambios entre académicos, estudiosos y creadores del TFA. 
Borgdorff, Henk. "El debate en la investigación en las artes". Traducido por Alfonso López Allosa, Cairon Revista de Estudios de Danza, núm. 13, 2010, pp. 25-46.

Converso Carlos. Entrevista personal. 31 de marzo de 2019

Curci Rafael. Entrevista personal. 4 de abril de 2019.

Franke, Anselm "Animism: Notes on an Exhibition". E-Flux, núm. 36, 2012, www.e-flux. com/journal/36/61258/animism-notes-on-an-exhibition/, consultado el 20 mayo de 2017.

Garcés, Marina. Un mundo común. Barcelona: Edicions Bellaterra, 2013.

Salazar, Rubén Darío. Entrevista personal 31 de marzo 2019.

Sánchez, José Antonio. "In-definiciones. El campo abierto de la investigación en artes". Artes. La Revista, vol. 12, núm. 19, 2013, blog.uclm.es/joseasanchez/2013/08/27/ in-definiciones-la-investigacion-en-artes-2013/, consultado el 15 de abril de 2020.

Sánchez, José Antonio, editor, et al. "La investigación en artes escénicas. Introducción". Cairon Revista de Estudios de Danza, núm. 13, 2010, pp. 5-13.

Swedzky, Javier. Entrevista personal 31 de marzo 2019. 